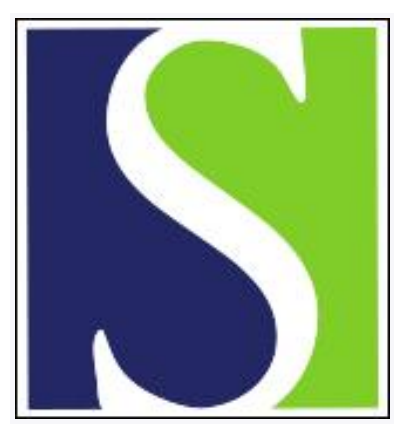

Scand J Work Environ Health 1990;16(4):258-269

https://doi.org/10.5271/sjweh.1786

Issue date: 01 Aug 1990

Chronic perceived work stress and blood pressure among Australian government employees.

by Chapman A, Mandryk JA, Frommer MS, Edye BV, Ferguson DA

Affiliation: National Institute of Occupational Health and Safety, Sydney, Australia.

The following article refers to this text: 2014;40(2):109-132

This article in PubMed: www.ncbi.nlm.nih.gov/pubmed/2389133

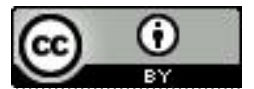




\title{
Chronic perceived work stress and blood pressure among Australian government employees
}

\author{
by Annie Chapman, BSW, ${ }^{1}$ John A Mandryk, PhD, ${ }^{1,2}$ Michael S Frommer, MB BS, MPH, \\ FACOM, ${ }^{1,2}$ Beryl V Edye, MB BS, DOH, FACOM, ${ }^{1}$ David A Ferguson, AM, MD, FRACP, \\ FACOM, FFOM ${ }^{1,2}$
}

\begin{abstract}
CHAPMAN A, MANDRYK JA, FROMMER MS, EDYE BV, FERGUSON DA. Chronic perceived work stress and blood pressure among Australian government employees. Scand $J$ Work Environ Health 1990;16:258 - 69. Prospective data on 2634 Australian government employees over five years were examined for the effects of chronic perceived work stress on blood pressure change. The study sample ( 2100 men and 534 women) represented $57 \%$ of the original volunteers, or $75 \%$ of those eligible after exclusion criteria were met. Data on perceived stress were obtained by questionnaire, and a principal component analysis produced six components: qualitative demands, quantitative demands, job control, future control, work support, and outside stress. Multiple linear regression, which controlled for determinants of blood pressure, tested the main effects and specific two-way interaction effects of the chronicity scores of the six components and 30 items. Many items but only some components were associated with blood pressure change. Sex and age differences were observed. The observed interactions between job demands and control provided equivocal support for the Karasek job-strain model. The women responded to workbased support, but not necessarily as predicted.
\end{abstract}

Key terms: blood pressure change, interactions, job control, job demands, principal components, prospective study, social support.

Although the links between hypertension and occupational stress remain controversial, there have been promising developments in this area of research. In particular, adverse stress is no longer thought to be synonymous with excessive work load, the focus now being upon key job characteristics and the ways in which these may interact.

Research based on Karasek's job-strain model has been influential. The model postulates that strain results not from a single aspect of the work environment, but from the joint effects of the demands of work (stressors) and environmental moderators of stress, particularly the range of decision-making freedom (control) available to the worker facing these demands $(1-3)$. When demands are high and control is low, mental strain and an increased risk of cardiovascular disease may arise. Several studies support this hypothesis $(4,5)$, while others do not $(6,7)$.

Social support has been found to moderate the relationship between environmental stress and psychological symptoms $(8,9)$. Men with elevated blood pressure have been found to report poor social networks more frequently than do normotensive men (10), and men who are both under strain and isolated may have

\footnotetext{
1 National Institute of Occupational Health and Safety, Sydney, Australia.

2 The University of Sydney, Sydney, Australia.
}

Reprint requests to: Dr JA Mandryk, National Institute of Occupational Health and Safety, GPO Box 58, Sydney NSW 2001, Australia. poor cardiovascular disease outcomes (11). LaRocco et al (9) proposed one possible social support model.

Sex differences in relation to the demand-control hypothesis have been reported (4), but most studies have been of one sex $(2,12,13)$.

Is age important? Klinger has observed some association between hassles or uplifts and current concerns or commitments $(14,15)$, and these are variables which tend to change with age (16).

In addition, little attention has been paid to analyzing chronic stress. Stress may have to be sustained if it is to have any impact on chronic disease (16-18). Results from the few longitudinal studies that have examined the effects of chronic stress on blood pressure are inconsistent $(5,19,20)$.

This paper presents results on the association of chronic perceived work stress over five years with blood pressure change over this period in a normotensive population. In particular, while the study was not conceived using the Karasek job-strain model $(1-3)$, the questions of whether the data agree with this model and with the social support model of LaRocco et al (9), and whether age and sex differences existed, were of interest.

\section{Subjects and methods}

The analysis was conducted as part of a larger fiveyear study of occupational determinants of hypertension and cardiovascular risk among 4607 Australian government employees working in Sydney (21). The subjects enrolled as volunteers between 1977 and 1980 and represented about $40 \%$ of those eligible to par- 
ticipate. The men came from eight diverse occupational groups (administrators, professionals, technicians, clerks, skilled tradesmen, blue-collar workers, tax investigators, and tax assessors), while the women came from two less diverse groups (office workers and technical or manual workers). Data collection took place during worktime visits to the study center in central Sydney.

\section{Procedures}

At each visit, the subjects underwent screening by a nurse, followed by a physician's medical assessment two weeks later. At the preliminary screening a selfadministered work-response questionnaire was completed. It was followed by interviewer-administered questions seeking demographic and occupational information and by anthropometric and physiological measurements. The subjects were requested to complete a biographical questionnaire at home. The questionnaire included items on medication use, alcohol consumption, and family history of cardiovascular disease. The medical assessment included a second blood pressure estimation, a physical examination focusing on the cardiovascular system, and a simple test of fitness.

\section{Blood pressure}

Blood pressure was measured with a Hawksley random-zero sphygmomanometer at both the screening and medical visits with methods for cardiovascular surveys as proposed by the World Health Organization (22). On each occasion two successive readings were taken on the right arm after 15 min of rest with the subject seated. The systolic blood pressure (SBP) was recorded at the appearance of the first Korotkoff sound and the diastolic blood pressure (DBP) at the disappearance of the sounds (Korotkoff phase V). The mean of the two readings was recorded. The mean of the readings thus recorded at the screening and medical visits was used in all the analyses. Each observer (nurse or doctor) was trained by the same physician (BVE), and measurement practice and instrument accuracy were monitored.

\section{Covariates}

Measures of determinants of hypertension were obtained. Weight was assessed with the subjects in ordinary clothing without shoes or a jacket. Fitness was estimated by an exercise test adapted from Master's Step Test (23) and graded from 1 (very fit) to 5 (unfit) (21). Also recorded were family history of stroke or hypertension, skinfold thickness (mean of upper arm, subscapular, and abdominal sites), alcohol consumption (10-g drinks/week), and education (completed secondary education).

\section{Work-response questionnaire}

A questionnaire which included 30 items, each on a graded five-point Likert scale, concerning feelings about the work environment and stress from sources outside work was completed at each visit (appendix 1). The items, selected from several sources (24-28), were regarded (in the mid-1970s) as particularly suitable for measuring perceived work stress in this heterogeneous population.

\section{Subjects}

The subjects were eligible for this analysis if they met several criteria. They had to attend follow-up visits three and five years after enrollment, they had to have complete relevant data, they had to remain in the work force, they were not to be receiving treatment for hypertension, and the women could not be pregnant. Data from the second- and fourth-year visits were not considered because, by study design, only about half of the cohort attended these visits. Of the 4607 subjects who enrolled, 39 did not return for the medical examination, 50 died within the five years, 432 had retired from the work force but continued to attend the study, 233 had retired and left the study, 290 were being treated for hypertension, and 35 women were pregnant on enrollment or at the fifth-year follow-up examination. Of the 3528 remaining subjects, 894 either failed to attend the three visits or had incomplete data. The study sample of 2100 men and 534 women thus comprised $57 \%$ of the original volunteers, or $75 \%$ of those who remained in the study after exclusions.

\section{Principal component analysis}

A principal component analysis (with varimax rotation) of 26 work-response items and three items describing stress outside work was conducted on firstvisit data from all the subjects who completed enrollment procedures $(\mathrm{N}=4568)$. This procedure was carried out both to reduce the complexity of the data and to confirm that the items belonged to constructs which described demand, control, support, and outside stress. The SAS (statistical analysis system) package was used for this and other analyses (29). Item 30 on support by spouse and relatives was not included at this stage because it did not fit conceptually with the other items. The results of this analysis are summarized in table A of appendix 2. Seven components were derived, which accounted for $55 \%$ of the variance. Unit weighting of items which loaded on a factor at $\geq 0.40$ was used to derive component scores (30). Item 6 on clarity of job responsibilities and item 12 on skill utilization were excluded because each loaded equally onto two components. These items were, however, included in the item analyses. The seventh component comprised one item only, which measured stress arising from the feeling that one's work was beyond understanding. This item was not regarded as a component but was 
included in the item analyses. Cronbach's alpha coefficients for the other six components ranged from $\mathbf{0 . 5 2}$ to 0.86 .

\section{Components}

Control (four items) referred to perceived influence over work rate and the extent to which one's job is interesting and varied. Quantitative demands (six items) referred to perceived time pressures, work load, and conflicting demands. Work support (six items) referred to perceived emotional support from co-workers and supervisors. Future control (four items) referred to perceived advancement opportunities, future job security, usefulness of skills, and satisfaction with pay. Qualitative demands (three items) referred to perceived pressures due to having to deal with and be responsible for other people, as well as being required to maintain too much mental concentration. Outside stress (three items) referred to perceived stress associated with family, friends, and financial problems.

\section{Chronicity}

Measures of chronic perceived stress were obtained as sums of the scores for each component and each item across the initial, three-year, and five-year visits. The reliability of this approach depended in part on the assumption that the reported level of stress was reasonably constant over the five years. As a test of this assumption, each component was divided into tertiles (high, moderate, and low) and the percentages of subjects who fluctuated between extremes across visits were examined. Only $2-8 \%$ of the subjects fluctuated to this extent, and therefore these scores should be reasonable estimates of chronic stress over the five years.

\section{Multiple regression}

Multiple linear regression models were developed for the dependent variables, the change in SBP over five years and the change in DBP over five years, with the contribution of initial blood pressure, age, family history of stroke or hypertension, education, weight, weight change, skinfold thickness, skinfold thickness change, fitness, fitness change, alcohol consumption, and alcohol consumption change being taken into account. Education and family history of stroke or hypertension were binary variables, while the other covariates were continuous. Data on the men and women were analyzed for three age groups, $<35$ years, $35-49$ years and $>49$ years, as well as for all the age groups combined. This stratification gave rise to eight models each for the change in SBP and the change in DBP. Only those covariates which were significant at the 0.05 level were retained.

The chronicity scores of the six components and 30 items were tested in each model. To test the Karasek and support hypotheses, we also tested the concep- tually appropriate two-way interaction terms, regardless of whether the specific main effects were significant. Because of the problem of multiple comparisons a significance level of 0.01 was chosen to determine inclusion of the stress variables.

\section{Results}

Subjects who either did not properly complete the work-response questionnaire or who met the eligibility criteria but failed to attend the follow-up were excluded because of the missing data. This group is compared with the actual study group in table 1 . The men with missing data were similar to the men included in the study in age, SBP, DBP, weight, and skinfold thickness. However, the alcohol consumption of the men with missing data was higher, they were less likely to report a family history of stroke or hypertension, they were less fit, and they were more likely to have been born in a non-English speaking country. Although a larger proportion of the women than the men had missing data, and the women with missing data were younger than the women included in the study, the two groups of women were otherwise similar.

\section{Components}

When each of the six-component chronicity scores was tested in the regression models, none was significant for all the men or all the women. However, sex and age differences were present (table 2). For young females, quantitative demands and work support were associated with a change in DBP. Among the older females, future control was associated with a change in DBP. None of the component interactions tested was significant.

\section{Items}

The results are presented for the 30 -item chronicity scores in table 3 . No item was associated with a change in SBP. For the total data on the women no item was associated with a change in DBP. For young women, however, work beyond understanding, work load, and unclear job responsibilities were significant, as were four work support items (not consulted by management, personal counseling at work, complaints to supervisor discouraged, and supervisor support). No item was associated with a change in DBP among the middle-aged and older women. For the total data on the men, only deadlines was significant. Among the young men, being required to deal with other people was significant. No significant effects were found for middle-aged or older men.

\section{Demand-control interactions}

To facilitate the interpretation of the significant demand-control interactions, these results are presented graphically in figure 1 . 
Table 1. Base-line characteristics of the study subjects and those for whom data were incomplete..$^{a}(\mathrm{SBP}=$ systolic blood pressure, $\mathrm{DBP}=$ diastolic blood pressure, $\mathrm{SE}=$ standard error of the mean)

\begin{tabular}{|c|c|c|c|c|c|c|c|c|c|c|c|c|c|c|c|c|c|c|c|}
\hline & \multirow{2}{*}{$\begin{array}{l}\text { Propor- } \\
\text { tion of } \\
\text { volun- } \\
\text { teers } \\
(\%)\end{array}$} & \multicolumn{2}{|c|}{$\begin{array}{c}\text { Age } \\
\text { (years) }\end{array}$} & \multicolumn{2}{|c|}{$\underset{\left(\mathrm{mmH} \mathrm{H}^{\mathrm{b}}\right.}{\mathrm{SBP}}$} & \multicolumn{2}{|c|}{$\begin{array}{c}\text { DBP } \\
\left(\mathrm{mmH}^{\mathrm{b}}\right)^{\mathrm{b}}\end{array}$} & \multicolumn{2}{|c|}{$\begin{array}{l}\text { Weight } \\
\text { (kg) }\end{array}$} & \multicolumn{2}{|c|}{$\begin{array}{c}\text { Alcohol } \\
\text { intake } \\
\text { (drinks } \\
\text { week) }\end{array}$} & \multicolumn{2}{|c|}{$\begin{array}{l}\text { Skinfold } \\
\text { thickness } \\
\quad(\mathrm{mm})\end{array}$} & \multicolumn{2}{|c|}{$\begin{array}{l}\text { Family } \\
\text { historye } \\
(\%)\end{array}$} & \multicolumn{2}{|c|}{$\begin{array}{l}\text { Non-English } \\
\text { speaking } \\
\text { origin } \\
(\%)\end{array}$} & \multicolumn{2}{|c|}{$\begin{array}{l}\text { Proportion } \\
\text { not fit } \\
(\%)\end{array}$} \\
\hline & & Mean & SE & Mean & SE & Mean & SE & Mean & SE & Mean & SE & Mean & $\mathrm{Se}$ & Mean & SE & Mean & SE & Mean & SE \\
\hline \multicolumn{20}{|l|}{ Men } \\
\hline $\begin{array}{l}\text { Included } \\
\text { in study } \\
(N=2100)\end{array}$ & 78.5 & 34.4 & 0.22 & 126.3 & 0.25 & 77.7 & 0.21 & 75.4 & 0.24 & 14.2 & 0.36 & 14.4 & 0.12 & 42.8 & 1.1 & 12.8 & 0.7 & 41.3 & 1.1 \\
\hline $\begin{array}{l}\text { With miss- } \\
\text { ing data } \\
(N=574)\end{array}$ & 21.5 & 32.4 & 0.44 & 127.2 & 0.50 & 77.0 & 0.46 & 75.6 & 0.48 & 16.3 & $0.77^{*}$ & 14.3 & 0.23 & 37.4 & $2.0^{*}$ & 16.7 & $1.6^{*}$ & 46.5 & $2.1^{\cdots}$ \\
\hline \multicolumn{20}{|l|}{ Women } \\
\hline $\begin{array}{l}\text { Included } \\
\text { in study } \\
(N=534)\end{array}$ & 62.5 & 31.9 & 0.49 & 114.3 & 0.53 & 71.3 & 0.40 & 59.2 & 0.42 & 4.7 & 0.35 & 18.0 & 0.28 & 43.9 & 2.1 & 17.1 & 1.6 & 75.8 & 1.9 \\
\hline $\begin{array}{l}\text { With miss- } \\
\text { ing data } \\
(\mathrm{N}=320)\end{array}$ & 37.5 & 28.4 & $0.56^{* *}$ & 114.3 & 0.74 & 70.0 & 0.54 & 60.0 & 0.65 & 4.1 & 0.40 & 18.0 & 0.40 & 38.1 & 2.7 & 17.6 & 2.1 & 74.1 & 2.4 \\
\hline $\begin{array}{l}\text { The person } \\
\text { tionnaire } \mathrm{p} \\
\text { nant wome } \\
1 \mathrm{mmHg} \approx \\
\text { One drink } \\
\text { d Mean from } \\
\text { \& Family hist } \\
\text { Lack of fitr } \\
\text { * } P<0.05 \text { (sig } \\
\text { and that w }\end{array}$ & $\begin{array}{l}\text { operly. T } \\
\text { n. } \\
\text { I33.322 P } \\
\text { quivalen } \\
\text { three sit } \\
\text { ory of st } \\
\text { ess (pul } \\
\text { nificant }\end{array}$ & $\begin{array}{l}\text { hey do r } \\
\text { t of } 10 \\
\text { es (sub } \\
\text { roke or } \\
\text { se rate } \\
\text { differend }\end{array}$ & $\begin{array}{l}\text { not inc } \\
\text { g of al } \\
\text { scapul } \\
\text { hypert } \\
\text { greater } \\
\text { ce betw }\end{array}$ & $\begin{array}{l}\text { lude vol } \\
\text { cohol. } \\
\text { ar, iliac } \\
\text { ension. } \\
\text { than } 1 \\
\text { veen the }\end{array}$ & $\begin{array}{l}\text { luntee } \\
\text { crest } \\
\text { izo be } \\
\text { e grou }\end{array}$ & $\begin{array}{l}\text { and } t \\
\text { simin } \\
\text { studi }\end{array}$ & eps & $\begin{array}{l}\text { ds). } \\
\text { nin of } \\
\text { at wit! }\end{array}$ & step & he st & 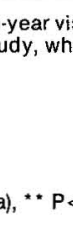 & 001 (s & . & ug $\mathrm{tr}$ & 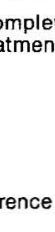 & for hyp & tens & on, & $\begin{array}{l}\text { ques- } \\
\text { preg- } \\
\text { udied }\end{array}$ \\
\hline
\end{tabular}

Table 2. Chronicity scores ${ }^{a}$ for the principal components of perceived job stress associated with a change in diastolic blood pressure ${ }^{b}$ - partial regression coefficients and the standard errors in models with significant covariates.

\begin{tabular}{|c|c|c|}
\hline & Coefficient & $\begin{array}{l}\text { Standard } \\
\text { error }\end{array}$ \\
\hline \multicolumn{3}{|l|}{ Women } \\
\hline \multicolumn{3}{|l|}{$<35$-year age group $(\mathrm{N}=357)$} \\
\hline $\begin{array}{l}\text { Quantitative demands } \\
\text { Work support }\end{array}$ & $\begin{array}{l}0.08^{\star *} \\
0.11^{* * *}\end{array}$ & $\begin{array}{l}0.03 \\
0.03\end{array}$ \\
\hline $\begin{array}{l}35-49 \text { age group }(N=112) \\
\geq 50 \text { age group }(N=65)\end{array}$ & $\cdot$ & $\cdot$ \\
\hline Future control & $-0.25^{* *}$ & 0.08 \\
\hline All age groups $(N=534)$ & $\cdot$ & $\cdot$ \\
\hline \multicolumn{3}{|l|}{ Men } \\
\hline $\begin{array}{l}<35 \text { age group }(N=1268) \\
35-49 \text { age group }(N=536) \\
\geq 50 \text { age group }(N=296)\end{array}$ & $\dot{.}$ & $\dot{.}$ \\
\hline All age groups $(N=2100)$ & $\cdot$ & . \\
\hline
\end{tabular}

Women. None of the interactions was associated with a change in SBP among the women with the three different age groups combined. For DBP change, only the one interaction between responsible for other people and advancement opportunities was significant $(\mathrm{P}<0.01)$. As dissatisfaction with responsibility increased, those with good opportunities for advancement had a greater DBP reduction than those with poor opportunities (figure 1a).
Table 3. Chronicity scores ${ }^{a}$ of the perceived job stress item associated with a change in diastolic blood pressure ${ }^{b}-$ partial regression coefficients and their standard errors in models with significant covariates.

\begin{tabular}{|c|c|c|}
\hline & $\begin{array}{l}\text { Coeffi- } \\
\text { cient }\end{array}$ & $\begin{array}{l}\text { Standard } \\
\text { error }\end{array}$ \\
\hline \multicolumn{3}{|l|}{ Womenc } \\
\hline \multicolumn{3}{|l|}{$<35$ age group $(\mathrm{N}=357)$} \\
\hline $\begin{array}{l}\text { Work beyond } \\
\text { understanding [29] }\end{array}$ & $0.87^{\star \star}$ & 0.31 \\
\hline $\begin{array}{l}\text { Management does not } \\
\text { consult [3] }\end{array}$ & $0.36^{\star *}$ & 0.13 \\
\hline Work load [15] & $0.42^{\star \star}$ & 0.16 \\
\hline $\begin{array}{l}\text { Complaints to supervisor } \\
\text { discouraged [2] }\end{array}$ & $0.44^{* *}$ & 0.15 \\
\hline Unclear job responsibilities [6] & $0.54^{\star \star *}$ & 0.19 \\
\hline Counseling at work [7] & $0.50^{* *}$ & 0.16 \\
\hline Supervisor support [1] & $0.51^{* * *}$ & 0.14 \\
\hline $35-49$ age group $(N=112)$ & $\cdot$ & $\cdot$ \\
\hline$\geq 50$ age group $(\mathrm{N}=65)$ & . & . \\
\hline \multicolumn{3}{|l|}{ Men $^{c}$} \\
\hline \multicolumn{3}{|l|}{$<35$ age group $(N=1268)$} \\
\hline Deal too much with people [23] & $0.32^{\star \star}$ & 0.10 \\
\hline $\begin{array}{l}35-49 \text { age group }(N=536) \\
\geq 50 \text { age group }(N=296)\end{array}$ & $\cdot$ & $\cdot$ \\
\hline \multicolumn{3}{|l|}{ All age groups $(N=2100)$} \\
\hline Deadlines [17] & $0.11^{* *}$ & 0.04 \\
\hline
\end{tabular}

a Significant item interactions presented in figures 1 and 2 .

b No associations were found with a change in systolic blood pressure.

c Item number in brackets as in appendix 1 .

** $P<0.01,{ }^{* * *} P<0.001$.

For women aged $<35$ years, none of the interactions were significant. 

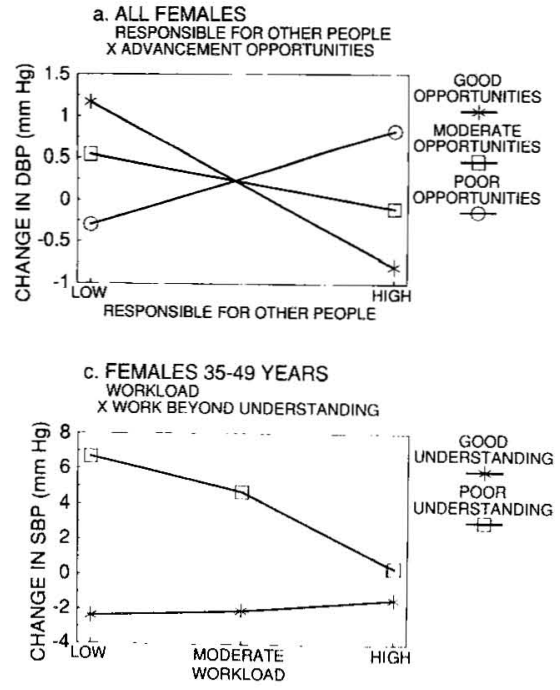

e. FEMALES $>49$ YEARS $X$ WORK BEYOND UNDERSTANDING
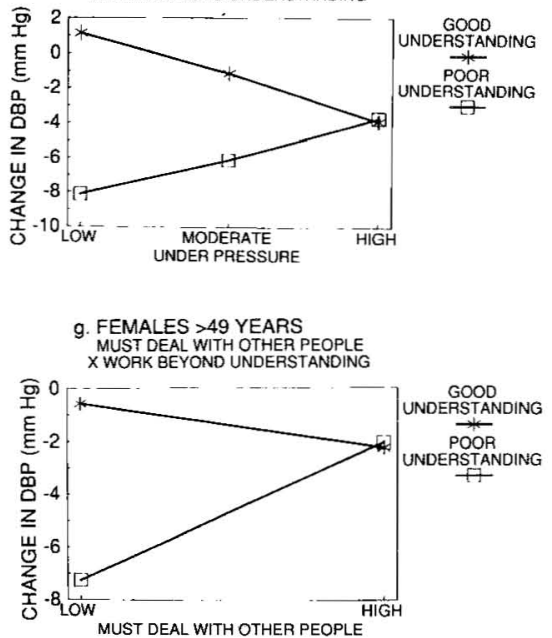

ALL MALES

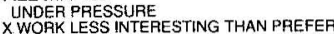

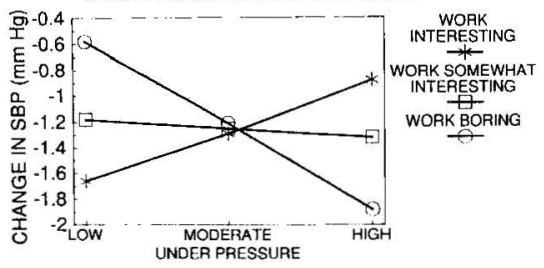

\section{k. MALES 35-49 YEARS INSUFFICIENT TIME TO COMPLETE WORK X ADVANCEMENT OPPORTUNITIES}

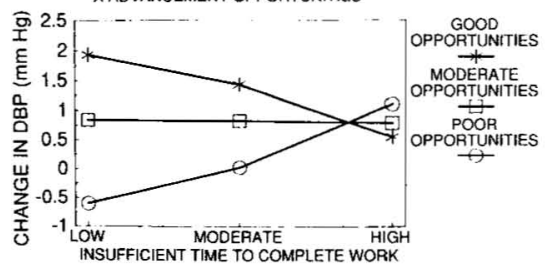

b. FEMALES 35-49 YEARS

$X$ WORK BEYOND UNOERSTANDING

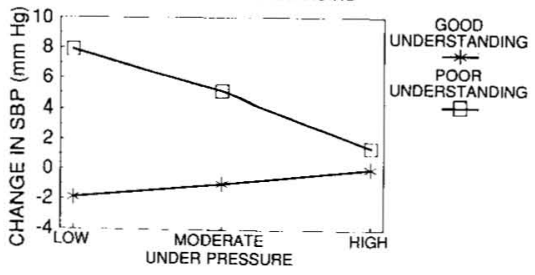

d. FEMALES 35-49 YEARS $X$ WORK BEYOND UNDERSTANDING

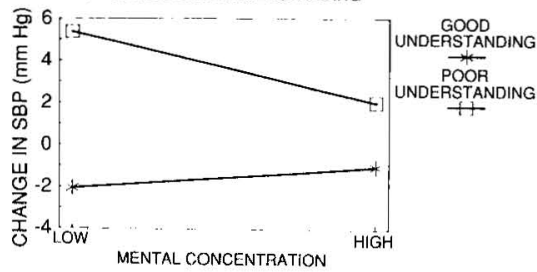

f. FEMALES $>49$ YEARS

$X$ LITTLE VARIATION IN WORK RATE
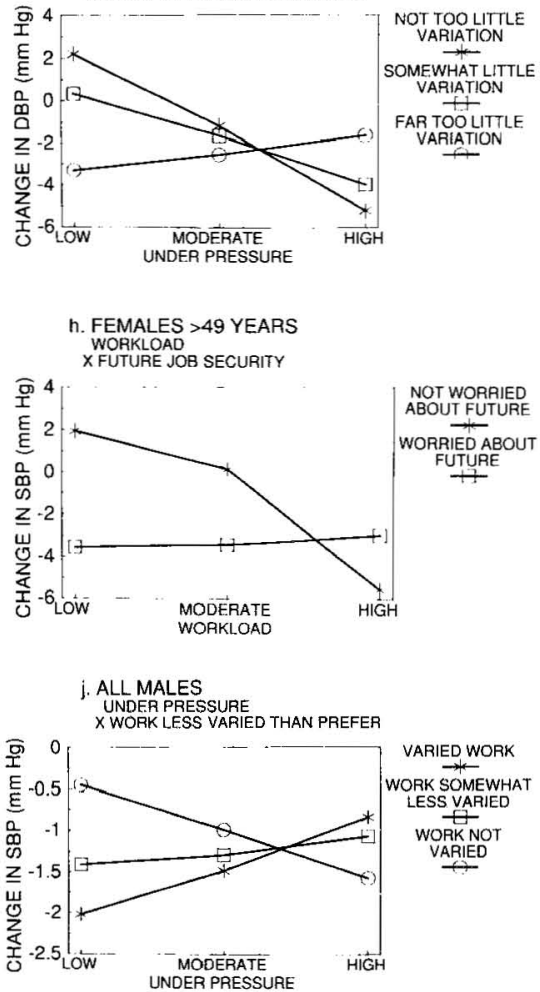

I. MALES $>49$ YEARS

INSUFFICIENT TIME TO COMPLETE WOR

$X$ WORRIED ABOUT FUTURE VALUE OF JOB SKILLS

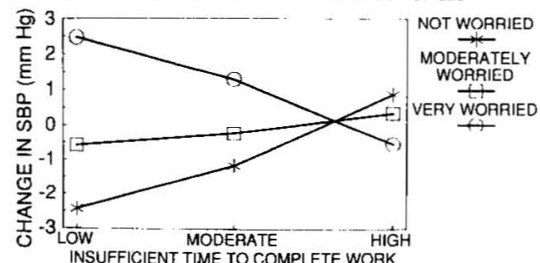

Figure 1. Significant $(P<0.01)$ interactions between the demand and control items associated with the change in systolic blood pressure (SBP) and the change in diastolic blood pressure (DBP). 
In the age group 35-49 years, none of the interactions among the women were associated with a change in DBP. For SBP change, however, work beyond understanding interacted with feeling under pressure $(\mathrm{P}<0.01)$, work load $(\mathrm{P}<0.01)$, and mental concentration $(\mathrm{P}<0.01)$. The direction of these results was similar. As perceived demand increased, the SBP decreased for those with poor understanding and increased for those with good understanding (figure 1b-1d). At the highest level of demand, however, understanding made little difference to the change in SBP. Notably, the reduction in SBP was consistently greater for those reporting good understanding.

For women aged $>49$ years, three interactions were associated with a change in DBP, namely, feeling under pressure with work beyond understanding $(\mathrm{P}<0.001)$, feeling under pressure with unvaried work rate $(\mathrm{P}<0.01)$, and deal too much with other people with work beyond understanding $(\mathrm{P}<0.01)$ (figure $1 \mathrm{e}-1 \mathrm{~g})$. As perceived demand increased, good understanding was associated with a reduced DBP, although, when demand was highest, understanding ceased to have any such association. Variation in work rate was also associated with reduced DBP as perceived pressure increased. For a change in SBP, one interaction was significant, work load with future job security $(\mathrm{P}<0.01)$ (figure $1 \mathrm{~h})$. As dissatisfaction with work load increased, those who were not worried about job security showed a reduction in their SBP.

Men. None of the interactions were associated with a change in DBP among all the men as a group. For SBP change, however, feeling under pressure interacted with interesting work $(\mathrm{P}<0.01)$ and with varied work $(\mathrm{P}<0.001)$ (figure $1 \mathrm{i}$ and $1 \mathrm{j}$ ). Blood pressure reduction was the greatest for those who reported low levels of work pressure and interesting work, although this advantage was lost when perceived work pressure increased.

Among the men aged $<35$ years, none of the interactions were significant.

For the men aged 35-49 years, none of the interactions was associated with a change in SBP. For DBP change, however, the interaction between insufficient time to complete work and advancement opportunities was significant $(P<0.01)$. As perceived time pressure to complete work increased, the DBP was reduced for those reporting good opportunities for advancement and increased for those reporting poor opportunities (figure 1k). However, if the time allowed for the work to be completed was sufficient, perceived good advancement opportunities were associated with an increase in DBP.

For the men aged $>49$ years, none of the interactions were associated with a change in DBP. For SBP change, however, insufficient time to complete work interacted with worry that job skills would cease to be of value $(\mathrm{P}<0.01)$. As perceived time pressure to com- plete work increased, the SBP was reduced among those who were worried about the future value of their job skills, but increased among those who were not worried (figure 11). For low perceived demand, the SBP was the most reduced for those not worried.

\section{Social support interactions}

Graphic representations of the significant social support interactions are presented in figure 2 .

Men. None of the interactions were significant for all ages combined nor for any age group of the men.

Women. None of the interactions among all the women as a group were associated with a change in SBP. For DBP change, however, the interaction between feeling under pressure and supervisor support was significant $(P<0.01)$. As perceived pressure increased, good support was associated with a greater reduction in DBP (figure 2a).

For the women aged $<35$ years, the change in DBP showed an interaction between spouse support and four items, namely, work beyond understanding $(\mathrm{P}<0.01)$, work faster than would prefer $(\mathrm{P}<0.001)$, insufficient time to complete work $(P<0.01)$, and work load $(P<0.01)$ (figure $2 b-2 e)$. The patterns of these interactions were similar. At low levels of stress, good support was associated with a greater reduction in DBP than was poor support. For high demand or understanding, however, support made little difference to the change in DBP. For SBP change, work faster than would prefer interacted with spouse support $(\mathrm{P}<0.01)$, and the pattern was similar to that for DBP change. Good support was associated with a greater reduction in SBP for low demands, and not for high demands (figure 2f).

For the women aged 35-49 years, none of the interactions were associated with a change in DBP. For SBP change, however, a number of support items were associated with work beyond understanding, namely, spouse support $(\mathrm{P}<0.001)$, supervisor support $(P<0.01)$, personal counseling at work $(P<0.01)$, and not consulted by management $(P<0.01)$ (figure $2 \mathrm{~g}-$ $2 j$ ). The patterns of these interactions were similar. As perceived understanding deteriorated, none of the support items buffered any increase in SBP, and in fact those with poor support had a greater reduction in SBP. Spouse support also interacted with work load for SBP change $(P<0.01)$. At a low perceived work load, good support was associated with a larger reduction in SBP than was poor support (figure $2 \mathrm{k}$ ). When the perceived work load was high, however, those with poor support had a greater reduction in SBP.

Among the women aged $>49$ years, none of the interactions were associated with a change in SBP. For DBP change, however, co-worker support interacted with four items, namely, feeling under pressure 
a. ALL FEMALES

UNDER PRESSURE
$X$ SUPERVISOR SUPPORT

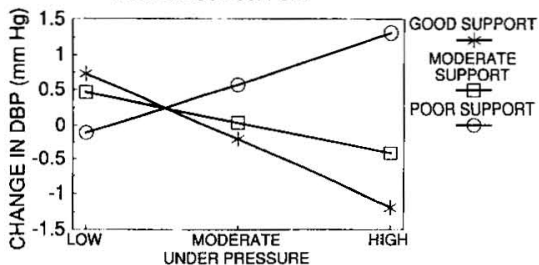

c. FEMALES <35 YEARS

WORK FASTER THAN WOULD PREFER $X$ SPOUSE SUPPORT

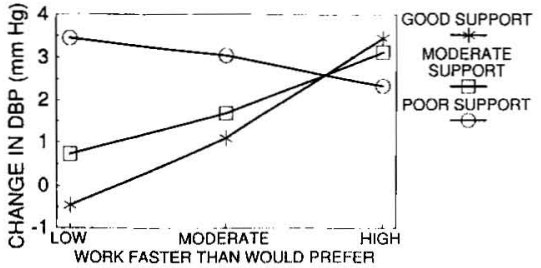

e. FEMALES < 35 YEARS

$X$ WORKLOAD
$X$ SPOUSE SUPPORT

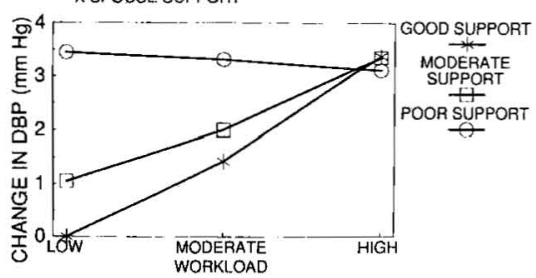

g. FEMALES 35-49 YEARS

WORK BEYOND UNDERSTANDING
$\times$ SPOUSE SUPPORT

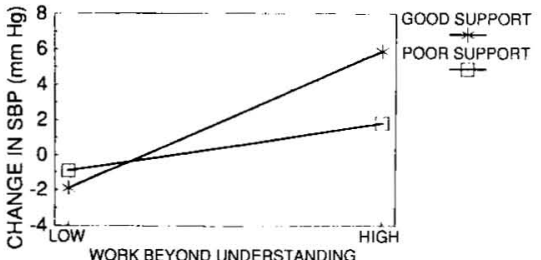

. FEMALES 35-49 YEARS WORK BEYOND UNDERSTANDING $X$ PERSONAL COUNSELLING

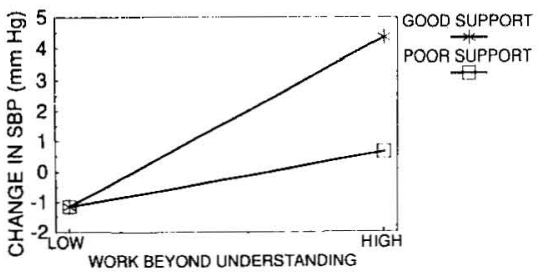

k. FEMALES 35-49 YEARS WORKLOAD $X$ SPOUSE SUPPORT

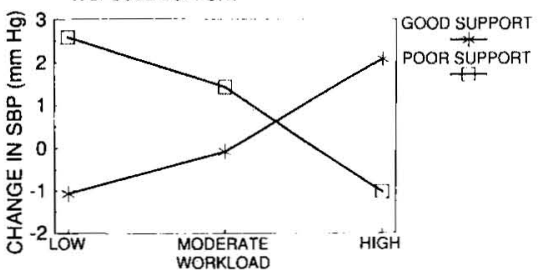

FEMALES $<35$ YEARS

WORK BEYOND UNDERSTANDING

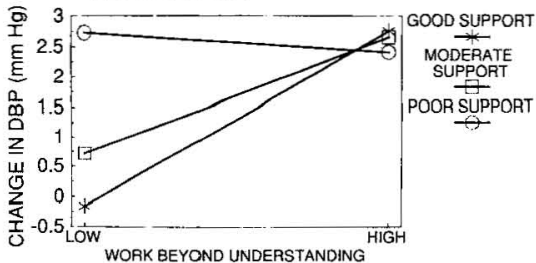

d. FEMALES $<35$ YEARS

INSUFFICIENT TME TO COMPLETE WORK

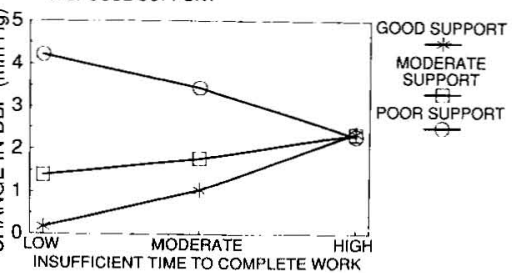

f. FEMALES $<35$ YEARS

WORK FASTER THAN WOULD PREFER

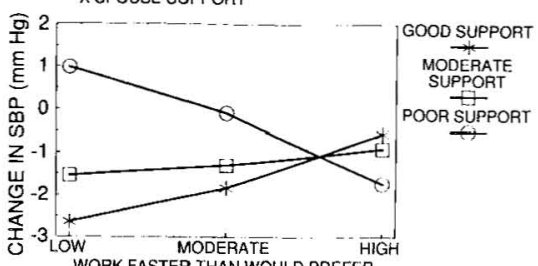

WORK FASTER THAN WOULD PREFEA

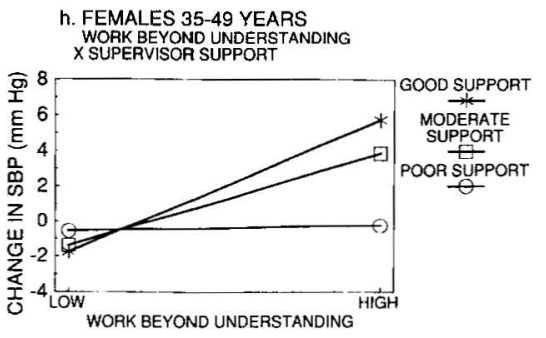

1. FEMALES $35-49$ YEARS

WORK BEYOND UNDERSTANDING

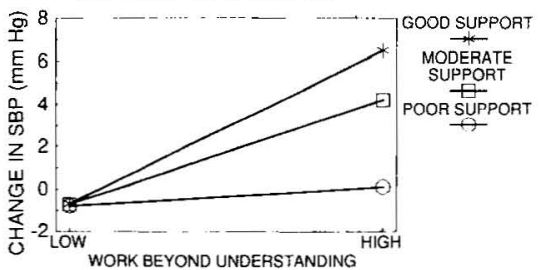

1. FEMALES $>49$ YEARS

UNDER PRESSURE

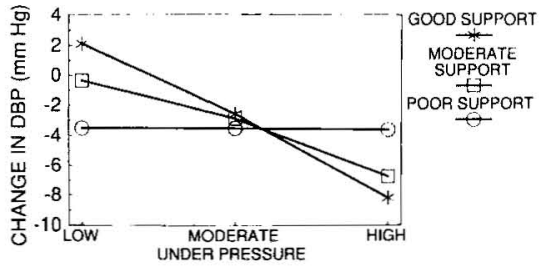

Figure 2. Significant $(P<0.01)$ interactions between the support items and the demand or control items associated with the change in systolic blood pressure (SBP) and the change in diastolic blood pressure (DBP). 
$(\mathrm{P}<0.001)$, work beyond understanding $(\mathrm{P}<0.01)$, work faster than would like $(\mathrm{P}<0.01)$, and conflicting demands $(\mathrm{P}<0.01)$ (figure $2 \mathrm{l}-2 \mathrm{o})$. As the perceived stress increased, good support was associated with a reduction in DBP. For one interaction, coworker support with conflicting demands (figure 2o), support had no impact on DBP reduction when perceived demand was high. The interaction of spouse support with feeling under pressure was also associated with a change in DBP $(P<0.01)$. As perceived pressure increased, good support was associated with a reduction in DBP (figure $2 p$ ).

\section{Discussion}

The Karasek model postulates that the greatest strain (or worst physiological outcome) is experienced by those persons with the combination of high demands and low control $(1-3)$. None of the 12 significant interactions of our study demonstrated this postulation, and in fact for half of the interactions the worst outcome was experienced by those with the combination of low demands and low control. Six of the 12 significant interactions demonstrated partial support for the Karasek model in that for those groups reporting low control, blood pressure increased as perceived demands increased (figure 1). For example, women who reported having too much responsibility for other workers (high demand) and poor opportunities for advancement (low control) experienced a greater increase in DBP than those women who reported a low level of responsibilities (low demand) combined with poor opportunities for advancement (low control) (figure 1a). For the other six interactions, the opposite of the Karasek prediction emerged in that the combination of high demands and low control was associated with a clearly better outcome than was low demands combined with low control.

Figure 1 highlights the inconsistencies between our findings and what was expected according to the $\mathrm{Ka}$ rasek model. One possibility for this lack of agreement is that some subjects were not conscious of their real feelings. The phenomenon of alexithymia has been discussed by Theorell et al, who found that an inability of 28-year-old men to differentiate feelings was associated with an elevated DBP (5). In a cross-sectional study of mostly male bus drivers, Winkleby et al (31) also reported "inverse" associations when high stress scores were associated with lower rates of hypertension.

Buffering was defined to be present if an interaction conformed to the hypothesis of LaRocco et al, in which different levels of social support have little effect in low stress situations, but as stress increases, good social support minimizes or reduces any possible negative outcome (9).

Five of the 16 significant social support interactions of our study demonstrated partial agreement with the social support model of $\mathrm{LaRocco}$ et al (figure 2). For example, when women reported feeling under pressure while having good supervisor support, their DBP was reduced more than among women with poor supervisor support (figure 2a). When work pressure was low, however, the amount of support ceased to have any differential effect. Conversely, two-thirds of the 16 interactions clearly did not accord with the social support hypothesis. For example, when stress was high, young women had a poor outcome regardless of the level of support, and it was only when stress was low that good support was associated with a greater reduction in DBP. Nevertheless, like LaRocco et al (9), we observed that work demands were moderated primarily
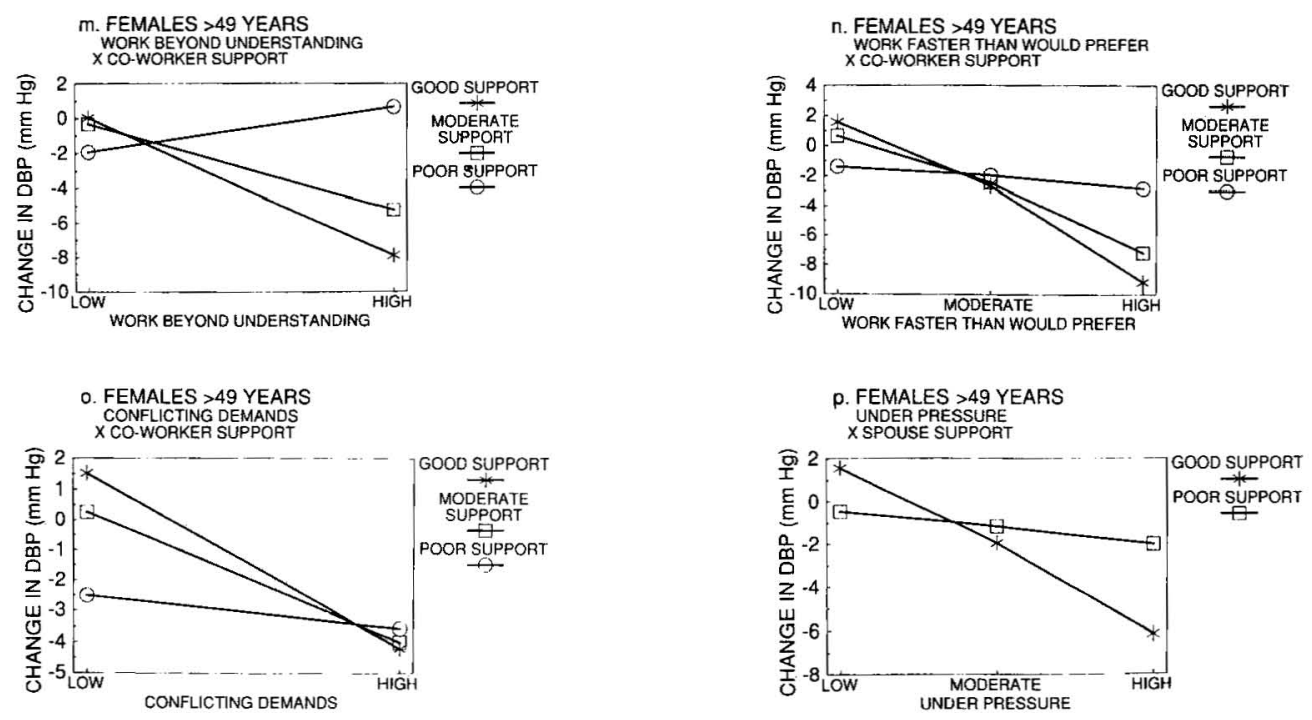

Figure 2. Continued. 
by work support rather than by outside support. Many of the older women in our study had worked together for a long time in telephonist and telegraphist pools where there was greater opportunity for interaction, and, although half of this group was married, support from family and friends was not found to moderate work demands. Support from family and friends was, however, more prominent for young women, only $28 \%$ of whom were married. Of the 16 support interactions, six involved work beyond understanding. With the exception of co-worker support, social support did not act as a buffer, and this stressor appeared to be exacerbated by good support. Workers who did not understand their work possibly felt more at ease with distant or indifferent supervisors; alternatively, inappropriate support may have been provided.

Hence, our evidence for a social support model is inconsistent. Perhaps social support is not summoned until needed, in which case any benefit is only apparent when stress has reached a critical level at which the subject and others realize that support is needed (9). Some results may be explained by the possibility that workers with good support perceived their work in a better light than it was, but nonetheless suffered physiological effects of stress. These inconsistencies highlight the need to obtain objective, as well as subjective, measures of stress.

In a previous cross-sectional analysis of this data set, Frommer et al (32) did not find any association between six similar components of perceived work stress and SBP among the men. The present longitudinal results, however, revealed many associations which differed between the men and the women. The most outstanding difference was associated with social support, which showed significant direct, as well as interactive, effects in the three female age groups but no effect among the men. For the women, social support was involved in five of the seven main effects and in 15 of the 24 interactions. These results echo findings of other studies that the effect of social support on health is greater among women $(33,34)$. In our study, work-based support was more effective as a buffer against work stress than was outside support (possibly because of its relevance and proximity to the source of stress).

Our results also revealed marked differences between the age groups. No item or two-way interaction was significant across all the age groups. One possible implication of this finding is that certain demands and constraints were present for some ages but absent for others. There was some consistency in the total pattern of associations in that the significant findings were most appropriate for the age groups in which they were found. For example, advancement opportunities can be important for men in their middle years, while future security can be a major concern in later life. Among middle-aged men, time pressure to complete work was moderated by opportunities for advancement. When such opportunities were perceived to be lacking, greater increases in blood pressure were observed. Men aged $>49$ years were sensitive to the combination of time pressure to complete work with whether their job skills would cease to be of value. Similarly, women aged $>49$ years formed the only female group for whom worry about future job security was associated with greater increases in blood pressure.

This study focused on 30 perceived stress items and six components derived from them. While there are arguments for condensing data to make analysis easier, as done by Johnson et al (11), who produced an "isostrain" variable from demand, control, and support, a major problem with any simplifying approach is that specific effects and interactions may be masked. This possibility may partly explain why the earlier crosssectional analysis of part of our data set (32) did not reveal any associations between the six perceived stress components and SBP, whereas many associations were detected in the present longitudinal analysis. The two analyses are consistent in that neither found associations of main effects with SBP. In the longitudinal analysis all the main effects were associated with DBP, while the two-way interactions were associated with both DBP and SBP, even when neither main effect was significant. This finding emphasizes the need to consider all relevant two-way interactions in studies of this type.

As with most studies in which blood pressure is analyzed as a continuous variable, certain exclusions had to be made (treatment for hypertension, pregnancy), while other persons retired, died, or had incomplete data. The analyses also adjusted for initial blood pressure, but whether or not the blood pressure was already elevated because of stress prior to entry to the study could not be easily ascertained.

The study has shown that estimates of chronic perceived work-related stress (over five years) are associated with blood pressure change (over the five years) after adjustment for initial blood pressure and other determinants of blood pressure. It is notable that the three measures of outside stress were not associated with blood pressure change, a finding suggesting the importance of the work-related factors. However, the three outside stress items may not have been sufficiently comprehensive to enable evaluation of the possible confounding effect of outside stress on the relationship between work stress and blood pressure change. While the sex and age differences observed were coherent with what one might expect, the pattern of associations was complex and is difficult to summarize. Support for the Karasek and social support models is equivocal, and therefore the notion that these models are oversimplifications and should not be regarded as general models is reinforced. The fact that interactions are important is clear, but the exact nature of such interactions requires further investigation. In a recent review, Kristensen (35) suggests that "Karasek's hypothesis has been strongly confirmed... [p 168]." 
However, Karasek and his co-workers (3) did acknowledge the model's limitations when they reiterated Kasl's 1981 challenge (36) that further research is required for a more-detailed understanding of the demand and control constructs.

\section{Acknowledgments}

We wish to thank the management, unions, and employees of Telecom Australia and the Australian Taxation Office; Professor G Berry, Professor in Epidemiology and Biostatistics, The University of Sydney; and Dr A Williamson, Senior Lecturer, Dr A-M Feyer, Lecturer, and Ms S Healey, Research Officer, National Institute of Occupational Health and Safety.

\section{References}

1. Karasek RA. Job demands, job decision latitude, and mental strain: implications for job redesign. Admin Sci Q 1979;24:285-308.

2. Karasek R, Baker D, Marxer F, Ahlbom A, Theorell T. Job decision latitude, job demands, and cardiovascular disease: a prospective study of Swedish men. Am J Public Health 1981;71:694-705.

3. Karasek R, Theorell T, Schwartz JE, Schnall PL, Pieper $\mathrm{CF}$, Michela JL. Job characteristics in relation to the prevalence of myocardial infarction in the US Health Examination Survey (HES) and the Health and Nutrition Examination Survey (HANES). Am J Public Health 1988;78:910-8.

4. Alfredsson L, Spetz C-L, Theorell T. Type of occupation and near-future hospitalization for myocardial infarction and some other diagnoses. Int $\mathbf{J}$ Epidemiol 1985;14:378-88.

5. Theorell T, Perski A, Ảkerstedt T, et al. Changes in job strain in relation to changes in physiological state: a longitudinal study. Scand J Work Environ Health 1988; 14:189-96.

6. Payne R, Fletcher BC. Job demands, supports, and constraints as predictors of psychological strain among schoolteachers. J Vocat Behav 1983;22:136-47.

7. Spector PE. Interactive effects of perceived control and job stressors on affective reactions and health outcomes for clerical workers. Work Stress 1987;1:155-62.

8. House JS, Wells JA, Landerman LR, McMichael AJ, Kaplan BH. Occupational stress and health among factory workers. J Health Soc Behav 1979;20:139-60.

9. LaRocco JM, House JS, French JRP Jr. Social support, occupational stress, and health. J Health Soc Behav 1980;21:202-18.

10. Theorell T, Alfredsson L, Knox S, Perski A, Svensson $\mathrm{J}$, Waller D. On the interplay between socioeconomic factors, personality and work environment in the pathogenesis of cardiovascular disease. Scand $\mathbf{J}$ Work Environ Health 1984;10:373-80.

11. Johnson JV, Hall EM, Theorell T. Combined effects of job strain and social isolation on cardiovascular disease morbidity and mortality in a random sample of the Swedish male working population. Scand J Work Environ Health 1989;15:271-9.

12. Billette A, Piche J. Health problems of data entry clerks and related job stressors. J Occup Med 1987;29:942-8.
13. Theorell T, Svensson J, Knox S, Waller D, Alvarez M. Young men with high blood pressure report few recent life events. J Psychosom Res 1986;30:243-9.

14. Klinger E. Consequences of commitment to and disengagement from incentives. Psychol Rev 1975;82:1-25.

15. Klinger E. Meaning and void: inner experience and the incentives in people's lives. Minneapolis, MN: University of Minnesota Press, 1977.

16. Bailey JM, Bhagat RS. Meaning and measurement of stressors in the work environment: an evaluation. In: Kasl SV, Cooper CL, ed. Stress and health: issues in research methodology. Chichester: John Wiley \& Sons, 1987:207-29.

17. Brody MJ, Natelson BH, Anderson EA, et al. Task force 3: behavioral mechanisms in hypertension. Circulation 1987;76(suppl 1):95-100.

18. House JS. Chronic stress and chronic disease in life and work: conceptual and methodological issues. Work Stress 1987;1:129-34.

19. Aro S. Occupational stress, health-related behavior, and blood pressure: a 5-year follow-up. Prev Med 1984;13: $333-48$.

20. Matthews KA, Cottington EM, Talbott E, Kuller LH, Siegel JM. Stressful work conditions and diastolic blood pressure among blue collar factory workers. Am J Epidemiol 1987;126:280-91.

21. National Institute of Occupational Health and Safety. Blood pressure study: handbook of tables. Canberra: Australian Government Publishing Service, 1987.

22. Rose GA, Blackburn H. Cardiovascular survey methods. Geneva: World Health Organization, 1968.

23. Moorehouse LE, Miller AT. Physiology of exercise. 6th ed. St. Louis, MO: CV Mosby Company, 1971:282-3

24. Eysenck HJ. The Eysenck personality inventory. San Diego, CA: Educational and Industrial Testing Service, 1968.

25. Jenkins CD, Rosenman RH, Zyzanski SJ. The Jenkins activity survey for health prediction. Chapel Hill, NC: David Jenkins, 1965.

26. Moos R. The family environment scale. Palo Alto, CA: Consulting Psychologists Press Inc, 1974.

27. Moos R. The work environment scale. Palo Alto, CA: Consulting Psychologists Press Inc, 1974.

28. Ferguson D. An Australian study of telegraphists' cramp. Br J Ind Med 1971;28:280-5.

29. SAS Institute Inc. SAS user's guide: version 5 edition. Cary, NC: SAS Institute Inc, 1985.

30. Afifi AA, Azen SP. Statistical analysis: a computer oriented approach. New York, NY: Academic Press, 1979:323.

31. Winkleby MA, Ragland DR, Syme SL. Self-reported stressors and hypertension: evidence of an inverse association. Am J Epidemiol 1988;127:124-34.

32. Frommer MS, Edye BV, Mandryk JA, Grammeno GL, Berry G, Ferguson DA. Systolic blood pressure in relation to occupation and perceived work stress. Scand J Work Environ Health 1986;12:476-85.

33. Broadhead WE, Kaplan BH, Sherman AJ, et al. The epidemiologic evidence for a relationship between social support and health. Am J Epidemiol 1983;117: $521-37$.

34. Wheeler RJ, Frank MA. Identification of stress buffers. Behav Med 1988;14(2):78-89.

35. Kristensen TS. Cardiovascular diseases and the work environment: a critical review of the epidemiologic literature on nonchemical factors. Scand J Work Environ Health 1989;15:165-79.

36. Kasl SV. The challenge of studying the disease effects of stressful work conditions [Editorial]. Am J Public Health 1981;71:682-4. 


\section{Appendix 1}

\section{Items from the work-response questionnaire}

The following 29 items from the work-response questionnaire were grouped in the principal component analysis:

1. Do you get less support than you would like on work troubles from your supervisor?

2. Do you feel discouraged from making a complaint to your supervisor?

3. Do management, including your immediate supervisor, not consult you as often as you would like on matters that affect you?

4. Do you get less support than you would like on work troubles from other people at work?

5. Do you get shown less appreciation than you would care to receive for good work?

6. Are you less clear than you would like to be on your job responsibilities?

7. Do you feel you cannot get as much counselling at work as you would like on personal problems or ill health?

8. Is your work less varied than you would like?

9. Is your work less interesting than you would like?

10. How boring is your work?

11. Is there too little variation in work rate for your liking?

12. Does your work offer less opportunity than you would like of using skills in which you were trained?

13. Does your job require you to work faster than you would like?

14. Do you have insufficient time each day to complete your work?

15. Do you have more work load than you care to handle?
16. How often do you feel under pressure in your work?

17. How often are there deadlines in your work?

18. Are conflicting demands put on you?

19. Do you feel insecure about the future of your job?

20. Do you feel that your job skills may cease to be of value in a few years?

21. How much do you feel that your opportunities for advancement are not as good as you would like?

22. Do you feel that you are paid much less than you should be in relation to what you do and what others get?

23. Are you required in your work to deal with others (including the public) more than you care to?

24. Do you have more responsibility than you care to have for the welfare, safety or security of other employees?

25 . Does your work require more mental concentration than you would like?

26. How much if any stress or worry have you had lately with your spouse or other person you are intimately involved with?

27. How much if any stress or worry have you had lately with other members of your family or close friends?

28. How much if any stress or worry have you had lately with money or home finance?

29. Is your work beyond your understanding or more complex than you can handle?

The following item was not included in the principal component analysis but was analyzed separately:

30. Do you get less support than you would like on work troubles from your spouse, relatives? 


\section{Appendix 2}

\section{Principal component analysis}

Responses to 29 items from the work-response questionnaire, listed in appendix 1 , were grouped by means of principal component analysis (table A), using a program for principal factoring without iteration from the SAS computer package. An item was considered to be represented in any given component if its loading was at least 0.40 . The following items loaded the most on the seven components:

Items $1-5,7$ (work support): component I Items 8-11 (control): component II
Items 13-18 (quantitative demands): component III Items 19-22 (future control): component IV Items $23-25$ (qualitative demands): component $\mathrm{V}$ Items 26-28 (outside stress): component VI Item 29: component VII

Items 6 and 12 each loaded equally on two components and were not retained. They were, however, tested individually in the multiple regression analyses.

Table A. Principal component solution (with varimax rotation) for the work-response questionnaire.

\begin{tabular}{|c|c|c|c|c|c|c|c|c|}
\hline \multirow{2}{*}{$\begin{array}{l}\text { Item } \\
\text { number }\end{array}$} & \multicolumn{7}{|c|}{ Component loading } & \multirow{2}{*}{ Communality } \\
\hline & 1 & II & III & IV & v & VI & VII & \\
\hline 1 & 0.76 & 0.14 & 0.10 & 0.05 & 0.01 & 0.04 & 0.01 & 0.61 \\
\hline 2 & 0.68 & 0.10 & 0.01 & 0.12 & 0.06 & 0.08 & 0.11 & 0.50 \\
\hline 3 & 0.66 & 0.12 & 0.20 & 0.15 & -0.03 & 0.01 & -0.06 & 0.51 \\
\hline 4 & 0.56 & 0.06 & 0.17 & 0.01 & 0.14 & 0.08 & 0.00 & 0.37 \\
\hline 5 & 0.57 & 0.21 & 0.17 & 0.20 & 0.16 & 0.03 & -0.19 & 0.50 \\
\hline 6 & 0.49 & 0.02 & 0.10 & 0.13 & 0.06 & 0.06 & 0.44 & 0.46 \\
\hline 7 & 0.48 & 0.15 & 0.03 & 0.10 & 0.19 & 0.18 & 0.09 & 0.34 \\
\hline 8 & 0.14 & 0.85 & -0.04 & 0.11 & -0.00 & 0.06 & -0.00 & 0.75 \\
\hline 9 & 0.15 & 0.84 & -0.01 & 0.16 & -0.03 & 0.05 & 0.01 & 0.75 \\
\hline 10 & 0.16 & 0.80 & -0.07 & 0.11 & -0.00 & 0.06 & 0.06 & 0.68 \\
\hline 11 & 0.08 & 0.73 & -0.02 & 0.02 & 0.03 & 0.06 & -0.02 & 0.54 \\
\hline 12 & 0.17 & 0.47 & 0.04 & 0.44 & 0.03 & 0.02 & -0.07 & 0.45 \\
\hline 13 & 0.05 & 0.01 & 0.73 & 0.03 & 0.17 & -0.01 & 0.12 & 0.57 \\
\hline 14 & 0.03 & -0.03 & 0.73 & -0.03 & 0.10 & 0.01 & 0.04 & 0.54 \\
\hline 15 & 0.10 & -0.01 & 0.69 & 0.02 & 0.29 & 0.05 & 0.07 & 0.57 \\
\hline 16 & 0.21 & -0.06 & 0.69 & 0.05 & 0.11 & 0.14 & 0.13 & 0.57 \\
\hline 17 & 0.08 & -0.04 & 0.64 & 0.04 & -0.11 & 0.07 & -0.16 & 0.46 \\
\hline 18 & 0.36 & -0.00 & 0.60 & 0.09 & 0.06 & 0.07 & 0.01 & 0.50 \\
\hline 19 & 0.18 & 0.07 & 0.07 & 0.62 & -0.06 & 0.15 & 0.29 & 0.53 \\
\hline 20 & 0.09 & 0.23 & 0.00 & 0.63 & 0.04 & -0.02 & 0.18 & 0.49 \\
\hline 21 & 0.28 & 0.29 & 0.04 & 0.57 & -0.00 & 0.03 & -0.24 & 0.54 \\
\hline 22 & 0.21 & -0.08 & 0.13 & 0.47 & 0.38 & 0.10 & -0.38 & 0.58 \\
\hline 23 & 0.15 & 0.03 & 0.09 & -0.03 & 0.65 & -0.01 & 0.03 & 0.45 \\
\hline 24 & 0.08 & -0.04 & 0.11 & 0.03 & 0.70 & 0.07 & 0.03 & 0.51 \\
\hline 25 & 0.06 & 0.03 & 0.25 & 0.04 & 0.60 & 0.04 & 0.31 & 0.52 \\
\hline 26 & 0.12 & 0.05 & 0.09 & -0.04 & 0.01 & 0.74 & -0.00 & 0.57 \\
\hline 27 & 0.07 & 0.07 & 0.11 & -0.01 & 0.00 & 0.68 & 0.10 & 0.49 \\
\hline 28 & 0.08 & 0.08 & 0.00 & 0.22 & 0.08 & 0.65 & -0.04 & 0.49 \\
\hline 29 & 0.03 & -0.02 & 0.13 & 0.10 & 0.23 & 0.04 & 0.68 & 0.54 \\
\hline $\begin{array}{l}\text { Propor } \\
\text { total va }\end{array}$ & $11.0 \%$ & $10.9 \%$ & $10.7 \%$ & $6.2 \%$ & $6.0 \%$ & $5.4 \%$ & $4.3 \%$ & $54.9 \%$ \\
\hline
\end{tabular}

Received for publication: 11 September 1989 